\title{
SOBRE LA UTOPÍA EN EL SOCIALISMO ${ }^{1}$
}

\author{
Juan Pro \\ (Universidad Autónoma de Madrid)
}

\section{RESUMEN}

La pregunta que se plantea en este trabajo es en qué sentido puede el socialismo ser utópico; o, dicho de otra manera, si puede el socialismo ser otra cosa que utópico. Se pregunta por el significado que dieron al término Utopía, apropiándose del nombre creado por Tomás Moro, quienes trescientos años después la aplicaron a un conjunto de autores del siglo XIX, a los que se dio en llamar genéricamente socialistas. Se analiza el sentido de la etiqueta de socialistas utópicos y, más particularmente, su utilización por Marx y Engels. El círculo se cierra con la relectura del legado marxista en términos de valoración positiva de la utopía en el periodo enmarcado por las dos guerras mundiales. El impulso crítico y ético que latía detrás de la Utopía original, latía también en la lucha contra el capitalismo que emprendieron los diversos socialismos del siglo XIX y del XX.

PALABRAS CLAVE: Socialismo, Utopía, Tomás Moro, Friedrich Engels, Marxismo

\section{On Utopia in Socialism}

\begin{abstract}
The question posed by this work is to what extent socialism can be utopian; o, in other words, if socialism can be anything but utopian. It explores the appropriation of the term Utopia, coined by Thomas More, to describe a number of nineteenth century authors, called generally socialists. The article analyse the meaning of the label of utopian socialists, in particular its use by Marx and Engels. The argument returns to positive conceptualisations of utopia through the work of a number of Marxistinspired authors writing between the two world wars. The drive that informed the original concept of Utopia, also informed the fight against capitalism that was sparked by the various socialisms in the Nineteenth an Twentieth centuries.
\end{abstract}

${ }^{1}$ Este trabajo se ha realizado en el marco del proyecto HAR2015-65957-P del Plan Nacional de I+D+i MINECO-FEDER (Historia del futuro: la utopia y sus alternativas en los horizontes de expectativa del mundo contemporáneo, siglos XIX-XXI). 
KEYWORDS: Socialism, Utopia, Thomas More, Friedrich Engels, Marxism

¿En qué sentido puede el socialismo ser utópico? ¿Puede el socialismo ser otra cosa que utópico? Merece la pena constatar que ha habido una asociación histórica entre el concepto de socialismo y el de utopía, y que esa asociación se produjo en el siglo XIX con un doble sentido. Merece la pena porque, para empezar, la asociación no resultaba evidente.

Utopia fue una palabra de significados y usos cambiantes desde que la creara Tomás Moro en 1516 para dar nombre a su isla imaginaria y para titular la obra en la que situaba ese no-lugar un modelo de sociedad ideal ${ }^{2}$. Durante más de tres siglos fue un nombre propio, que en ocasiones servía para un símil: citando aquella palabra de origen griego, Utopía, las elites cultas que conocían el referente de Moro indicaban que consideraban algo de imposible realización aunque tal vez excelente como concepción ideal. Solo a partir de la década de 1820 se empezó a usar también como sustantivo común de significado similar, primero en francés y luego en español ${ }^{3}$.

Socialismo apareció después: el término se empezó a usar en los años treinta del siglo XIX para referirse a las ideas de quienes se preocupaban por la "cuestión social" desde una perspectiva crítica hacia el orden económico capitalista y hacia el orden político liberal que lo sostenía desde el triunfo de las revoluciones. Es cierto que en el primer texto en el que se mencionó la palabra socialismo, en 1834, por Pierre Leroux, se aplicaba a las tendencias antiindividualistas de la Francia de su tiempo ${ }^{4}$; pero, para cuando el término se popularizó a comienzos de los años cuarenta, en obras como las de Reybaud (en francés), Owen (en inglés) o Von Stein (en alemán) ${ }^{5}$, socialismo no denominaba a ninguna ideología concreta, sino a un entorno difuso que englobaba a todos los que buscaban una alternativa al sistema capitalista que evitara sus consecuencias sociales más escandalosas, o aún más, una regeneración social y moral

\footnotetext{
${ }^{2}$ Tomás Moro, De optimo reipublicae statu, deque nova insula V topiae (Lovaina: Dirk Martens, 1516).

${ }^{3}$ Juan Pro. "Utopia in the Spanish Language: The Origin of a Word, the History of an Idea", en Utopias in Latin America: Past and Present, ed. J. Pro (Brighton-Portland: Sussex Academic Press, 2018), 15-35.

${ }^{4}$ Pierre Leroux, "De l'individualisme et du socialisme", Revue Enciclopedique (1834). Ed. moderna en Pierre Leroux, De l'égalité, précédé de De l'individualisme et du socialisme (Ginebra: Slatkine, 1996).

${ }^{5}$ Louis Reybaud, Études sur les reformateurs ou socialistes modernes, Saint-Simon, Charles Fourier, Robert Owen (París: Guillaumin, 1840). What is Socialism? And what Would be Its Practical Effects Upon Society? A Correct Report of the Public Discussion Between Robert Owen \& Mr. John Brindley, Held in Bristol, on the 5th, 6th, and 7th of January, 1841 (Londres: Home Colonization Society, 1841). Lorenz von Stein, Der Sozialismus und Kommunismus des heutigen Frankreichs (Leipzig, Otto Wiegand, 1842).
} 
de la humanidad (y ahí cabían juntos desde los reformistas de talante tecnocrático hasta los primeros anarquistas y comunistas). Pensemos que hasta los años sesenta de aquel siglo XIX no se produciría el entronque definitivo del pensamiento socialista con el movimiento obrero, que en las décadas anteriores constituían fenómenos separados.

Desde esta perspectiva, la asociación entre el socialismo y la Utopía de Tomás Moro no resultaba descabellada. A fin de cuentas, la obra de Moro nacía también de una crítica a la modernidad de su tiempo, al capitalismo incipiente que asomaba en la Inglaterra del siglo XVI. Y, frente al desorden creado por las transformaciones del mundo moderno, proponía un orden racional basado en sólidos principios morales como harían después los socialistas-, con soluciones como la abolición de la propiedad privada, que enseguida se considerarían típicamente socialistas.

Tan lógica resultaba la asimilación entre socialismo y utopía que ésta se produjo en un doble sentido: desde dentro del movimiento socialista, se habló de socialismo utópico; mientras que desde fuera, los adversarios del socialismo hablaban de la utopía socialista.

Efectivamente, la asimilación entre socialismo y utopía empezó a proponerse desde los años 1830, debida inicialmente a Adolphe-Jerôme Blanqui (el economista, hermano mayor de Louis-Auguste Blanqui), que fue quien empleó por primera vez la expresión socialisme utopique en un texto de $1837^{6}$. Esta expresión hizo fortuna merced a la obra de Marx y Engels: Marx la empleó en el capítulo $3^{\circ}$ del Manifiesto Comunista (1848), donde dice cosas como: «La importancia del socialismo y comunismo críticoutópico es inversamente proporcional al desarrollo histórico (...). Sueñan todavía en la realización, a modo de ensayo, de sus utopías sociales.... ${ }^{7}$. Y sobre todo, se difundió mediante el folleto de Friedrich Engels titulado Del socialismo utópico al socialismo científico. Aquel folleto se publicó en francés en 1880, a instancias de Paul Lafargue, sobre tres capítulos del Anti-Düring de los años setenta; e inmediatamente fue traducido al español y al polaco (luego, también a otras lenguas) ${ }^{8}$. El argumento consistía en aplicar la etiqueta de utópicos a los grandes pensadores socialistas anteriores a Marx y Engels, ejemplificados en Saint-Simon, Fourier y Owen.

La analogía con la Utopía de Moro se hacía para subrayar que se trataba de un socialismo de pura fantasía, bienintencionado, pero ingenuo e inviable. Socialismo utópico era, así, un concepto peyorativo, que servía para descartar como anticuado e inútil a aquel socialismo anterior, contraponiéndolo al que proponían los propios Marx y

\footnotetext{
${ }^{6}$ Adolphe-Jérôme Blanqui, Histoire de l'économie politique en Europe depuis les anciens jusqu'à nos jours, suivie d'une bibliographie raisonnée des principaux ouvrages d'économie politique (París, Guillaumin, 1837). Traducido en España dos años más tarde como: Historia de la economia política en Europa: desde los tiempos antiguos hasta nuestros dias, seguida de una bibliografía razonada de las principales obras de dicha ciencia (Madrid: Imp. de Nicolás Arias, 1839).

7 Apartado 3.3: "El socialismo y el comunismo crítico-utópicos". Edición de Pedro Ribas: Karl Marx y Friedrich Engels, Manifiesto Comunista (Madrid: Alianza Editorial, 2001), 82.

${ }^{8}$ Las citas de esta obra proceden de la edición española: Federico Engels, Del socialismo utópico al socialismo cientifico (Madrid: Ricardo Aguilera, 1969).
} 
Engels. Para este creaban la pretenciosa etiqueta de socialismo cientifico; que sería el socialismo basado en las leyes que supuestamente rigen el movimiento histórico, y que Marx y Engels creían haber descubierto de manera definitiva con el materialismo histórico y la lucha de clases. Socialismo centrado en la crítica -también supuestamente científica- del sistema económico capitalista, para desvelar su mecanismo de explotación y comprender su dinámica destructiva, en lugar de "perder el tiempo" imaginando cómo sería la sociedad perfecta del futuro. Socialismo, además, de clase, que prepara la destrucción revolucionaria del sistema por parte del proletariado, en vez de "soñar" con la emancipación indiferenciada de la humanidad. El socialismo marxiano, pues, reprochaba a sus precursores -al llamarles utópicos- que fantasearan sobre la sociedad futura en lugar de destinar sus esfuerzos a preparar la revolución; de manera que no se tomaba el nombre de Moro en vano, sino con el sentido descalificador y negativo que la palabra había adquirido en el lenguaje corriente de la primera mitad del siglo XIX.

Saint-Simon, Fourier y Owen eran elogiados por Engels como pensadores geniales en la crítica del capitalismo desde principios del siglo XIX. ${ }^{9}$ Pero, a continuación, se descartaba su planteamiento como burgués en el fondo. Según Engels, para estos socialistas -que nosotros llamaríamos más bien románticos o tempranos, por la época en que surgió su pensamiento-

Tratábase (...) de descubrir un sistema nuevo y perfecto de orden social, para implantarlo desde fuera, por medio de la propaganda, y a ser posible, con el ejemplo, mediante experimentos que sirviesen de modelo. Estos nuevos sistemas sociales nacían condenados a moverse en el reino de la utopía; cuanto más detallados y minuciosos fueran, más tenían que degenerar en puras fantasías ${ }^{10}$.

Más adelante, criticaba la ingenuidad con la que «el socialismo es, para todos ellos, la expresión de la verdad absoluta, de la razón y de la justicia, y basta con descubrirlo para que por su propia virtud conquiste el mundo» ${ }^{11}$.

Sin embargo, al mismo tiempo que -desde dentro del ámbito socialista- se creaba la expresión socialismo utópico con esta intención peyorativa, socialismo y utopía se asociaban también en otro sentido, en realidad mucho más difundido, desde fuera del socialismo: el sentido que expresa la etiqueta utopía socialista. Porque, efectivamente, tan pronto como apareció el socialismo, los términos utopía y utópico se utilizaron para descalificar a todo el socialismo -incluido el marxista- y no solo a una parte del mismo. En España tenemos muchos ejemplos desde los años cuarenta, como este de Nicomedes Pastor Díaz:

\footnotetext{
9 Ibídem, 45: "geniales gérmenes de ideas".

${ }^{10}$ Ibidem, 45.

${ }^{11}$ Ibidem, 53.
} 
... si hubiera un rincón en el mundo donde se realizara la república de Platón, o alguna de esas brillantes utopías socialistas que han soñado ciertos novadores de nuestros días, el derecho de propiedad para aquellos asociados no existiría... ${ }^{12}$

Y los ejemplos se volvieron mucho más frecuentes a partir del Sexenio revolucionario de 1868-74, cuando el socialismo adquirió fuerza y organización en España. Como en estas palabras de Emilio Castelar:

Más tarde vino la lucha que ahora también nos separa, y en aquel gran debate, mientras unos republicanos se encontraban de parte de la utopía socialista, que prometía no sé qué edenes que no han podido traer a la tierra, yo me encontraba de parte de los individualistas ${ }^{13}$.

Esta equiparación entre el conjunto del movimiento socialista y la Utopía de Tomás Moro venía de lo que podemos llamar el reproche utópico ${ }^{14}$. Es decir, el sentido negativo con el que circulaba en la época el término utopía como fantasía irrealizable; especialmente aplicado a los casos en los que esa supuesta fantasía iba dirigida a imaginar un modelo alternativo de organización social, como Moro había hecho en 1516 .

En centenares de textos impresos a lo largo de los siglos XIX y XX, este reproche utópico implicaba la descalificación de los proyectos de cambio social por dos motivos. Por un lado, al decir que eran utópicos, se acusaba a los proyectos socialistas de ingenuos y, por lo tanto, engañosos, ya que su realización sería -por definiciónimposible. Por otro lado, frecuentemente se añadía la nota de que no solamente eran ficciones ilusorias, sino - peor que eso- además eran peligrosas, porque extraviaban a las masas, llevándolas a perseguir quimeras irrealizables, y porque podían conducir a mundos no tan ideales, impregnados de autoritarismo, arbitrariedad, injusticia y hasta, llegado un punto, totalitarismo.

El sintagma utopía socialista fue mucho más frecuente en la prensa del XIX que el hoy más conocido de socialismo utópico; y acabó convirtiendo al socialismo en el núcleo duro del concepto de utopía. Fue esa asociación con el socialismo la que amplió significativamente el alcance del concepto de utopia hasta darle la forma con la que ha llegado hasta nosotros y se ha convertido en objeto especializado de un campo científico denominado de "estudios utópicos" (Utopian Studies).

\footnotetext{
${ }^{12}$ Nicomedes Pastor Díaz. "Discurso sobre la devolución de los bienes al clero" (1845), en Discursos (Barcelona: Anthropos-Fundación Caja Madrid, 1996), 339-340. El mismo autor empleó también varias veces el concepto de "utopía socialista" en Los problemas del socialismo: lecciones pronunciadas en el Ateneo de Madrid en el curso de 1848 a 1849 (Madrid: Imp. de Manuel Tello, 1867).

${ }^{13}$ Diario de sesiones de las Cortes constituyentes de la República española, Legislatura 1873-1874, n 99, 2 de enero de 1874, 2.510-2.511.

14 Similar al "reproche de utopismo" del que habla Graciela Fernández, Utopía. Contribución al estudio del concepto (Mar del Plata: Suárez, 2005), 192.
} 
Recapitulemos el proceso por el que se produjo esta ampliación de significados: el primer paso había sido pasar del uso metafórico de la Utopía de Tomás Moro (mencionada habitualmente en mayúscula, sin tilde y en cursiva, como correspondía a un nombre propio procedente de otra lengua) a un uso más propio como nombre común que, desde los años 1820 o 1830, equiparaba los planteamientos a los que se aplicaba con aquella obra de ficción.

El segundo paso lo apreciamos cuando la palabra utopía entra ya en los diccionarios, en las décadas de 1850 y 1860, definida como "cualquier idea que es aceptable en teoría, aunque imposible de realizar" ${ }^{\text {"15. }}$. Este paso, que -como venimos diciendo- solo pudo darse por la asociación del socialismo con la idea de utopía, implicaba que este concepto dejara de limitarse a un género literario de ficción consistente en describir sociedades imaginarias perfectas en lugares remotos $\mathrm{O}$ inexistentes. En adelante, el significado de utopía conllevaba un viaje en el tiempo y no en el espacio, pues la sociedad perfecta de la que se hablaba no se imaginaba ya-como la de Moro- en un no-lugar, sino en un tiempo futuro, en el cual se realizarían los ideales alternativos que se propugnaban ${ }^{16}$. Al mismo tiempo que se producía ese desplazamiento desde el utopismo clásico de ficción hacia el utopismo moderno de esperanza, la irrupción del socialismo había puesto en el centro de la utopía la crítica política y social (que en las utopías del Renacimiento y del Barroco, como la misma de Moro, tenía forzosamente que expresarse con más cautela, soterrada bajo las licencias de arte y de la ficción). A partir del siglo XIX, el objeto de la utopía sería la crítica del modelo sociopolítico existente, por la vía de proponer un modelo alternativo más deseable.

Desde que se vinculó al socialismo, por tanto, el concepto de utopía dejó de referirse necesariamente a textos de ficción similares al de Tomás Moro, y pasó a

\footnotetext{
${ }^{15}$ Voz "Utopía", en Diccionario enciclopédico de la lengua española: con todas las vozes, frases, refranes y locuciones usadas en España y las Américas españolas, en el lenguaje común antiguo y moderno; las de ciencias, artes y oficios; las notables de historia, de biografía, de mitolojia y geografia universal, y todas las particulares de las provincias españolas y americanas, dir. Eduardo Chao (Madrid: Imprenta y Librería de Gaspar y Roig, 1853-1855), vol. 2. Muy similar, por los mismos años, era la definición que daba Rafael María de Baralt, Diccionario de galicismos: 0 sea de las voces, locuciones y frases de la lengua francesa que se han introducido en el habla castellana moderna (Madrid: Imprenta Nacional, 1855): «Sistema que principalmente se funda en lucubraciones sin fundamento real en la historia, en las costumbres, o en las propensiones humanas, si bien formadas con el buen deseo de mejorar la condición del hombre y el estado de los pueblos». O la que, más tardíamente, dio la Real Academia Española en la $11^{a}$ edición del Diccionario usual de la lengua castellana (1869): «Plan, proyecto, sistema ó doctrina que halaga en teoría, pero cuya práctica es imposible».

16 Posteriormente, teóricos del siglo XX plantearían que este cambio de la utopía de lugar a la utopía de futuro dio nacimiento a la utopía contemporánea, por contraste con las utopías clásicas de la Edad Moderna. La idea la popularizó Karl Mannheim en Ideología y utopía. Introducción a la sociología del conocimiento (1929) (ed. de Madrid: Aguilar, 1973), 208-209; citando como su autor original a Alfred Doren. "Wunschräume und Wunschzeiten”, en Vorträge der Bibliothek W arburg 1924/ 25 (Leipzig-Berlín: Teubner, 1927), 158-205. Este argumento, generalmente aceptado en el campo de los estudios utópicos desde la segunda mitad del siglo XX, sitúa como la primera utopía temporal de este tipo moderno a la ucronía de Louis-Sébastien Mercier, L'an deux mille quatre cent quarante. Rêve s'il en fût jamais (Londres, en realidad, Ámsterdam: E. Van Harrevelt, 1771).
} 
englobar otras formas de crítica del orden establecido y búsqueda de alternativas, formas que pueden ser también acción, práctica, experiencia, tengan o no tengan detrás un texto utópico que las inspire. Ya no se considerarían utopías solamente las descripciones literarias de sociedades inexistentes, sino que serían también utopías ciertas comunidades experimentales y ciertos movimientos sociales.

Lo serían las comunidades experimentales de pequeña escala que, con carácter modélico, construyeron desde el siglo XIX multitud de movimientos, tanto socialistas propiamente dichos (falansterios fourieristas, comunidades icarianas, colonias owenistas) como anarquistas, sionistas y andando el tiempo, tolstoianos, gandhianos, hippies, ecologistas, etc. Esto, que podríamos llamar la micro utopia, corresponde a las prácticas comunitarias de pequeña escala que habían inspirado los socialistas llamados utópicos por Marx y Engels. Y está relacionado con el precedente de Tomás Moro a través de la imagen de la isla del libro II de la Utopía: ese lugar separado del resto del mundo en el que resulta posible ensayar soluciones alternativas que sirvan de ejemplo.

Y también son utopías los movimientos sociales de carácter revolucionario, que creen posible un modelo político, económico y social radicalmente distinto del actual, que consideran inadmisible. Esto es lo que podríamos llamar macro utopias, en la medida en que se trata de movimientos de masas, de gran escala. Su núcleo duro lo constituye la historia del socialismo, con sus diversas variantes y escisiones, incluidos el anarquismo y el comunismo. En tiempos más recientes, podríamos incluir entre estas utopías macro a los llamados "nuevos movimientos sociales" (pacifistas, ecologistas, feministas, etc.). Aunque su relación con la Utopía de Tomás Moro parezca más indirecta, también aquella obra proponía un modelo alternativo de sociedad, y en su libro I había una crítica al orden establecido en la Inglaterra de su tiempo.

Para llegar al concepto actual de la utopía faltaba, por último, un tercer paso, que empezó a darse en las últimas décadas del siglo XIX y las primeras del siglo XX. El paso de la significación meramente negativa del concepto de utopía, que solo permitía emplearlo para descalificar opiniones ajenas, a una recuperación del concepto en positivo, por el cual algunos pensadores y activistas empezaron también a autodenominarse utópicos. Esto responde a un fenómeno histórico bastante frecuente, por el cual los calificativos lanzados sobre un colectivo con intención denigratoria, acaban contribuyendo a dar identidad a ese colectivo y son asumidos con orgullo como propios con una resignificación positiva. Tanto los anarquistas como los socialistas, acusados por sus adversarios de perseguir utopías, acabaron aceptando que así era y reivindicando las connotaciones positivas del término. En parte, siguiendo el principio que había expresado Victor Hugo de que las utopías de hoy serán las realidades del mañana ${ }^{17}$ algo que el rápido progreso de la ciencia y de la técnica permitía comprender por analogía como principio válido también para los asuntos políticos y sociales. El género de la ciencia-ficción, cada vez más popular, acostumbró a la gente a pensar el

${ }_{17}$ Victor Hugo, Los miserables (1862) (ed. de Madrid: Alianza Editorial, 2013), vol. 1, 711 (3 ${ }^{\mathrm{a}}$ parte, libro 4, cap. I). 
futuro en esos términos de transformación profunda de la vida en todos los órdenes. Por eso consideramos que existe una relación muy estrecha entre la utopía y la cienciaficción. Pero en parte también porque la utopía revolucionaria del socialismo dejó de ser vista como algo de imposible realización: así lo demostraron, desde finales del XIX, los socialdemócratas europeos que, inspirados por la tendencia revisionista, empezaron a aplicar un programa reformista gradual, cuyo pragmatismo resultaba innegable, relegando el programa máximo a un futuro indeterminado como utopía que marcaba el rumbo pero no exigía una aplicación inmediata; y así lo demostraron también, desde 1917, los bolcheviques rusos, que aportaron a la rama comunista del socialismo en todo el mundo el ejemplo de una realización efectiva del programa revolucionario.

Después de estos cambios, quedaba asentado el concepto de utopía que hoy manejamos, complejo y ambiguo por los diversos usos que permite; pero sin duda más rico que la antigua etiqueta conservadora que se lanzaba para descalificar cualquier proyecto de cambio. La situación estaba madura para que, en los cincuenta años que mediaron entre el final de la Primera Guerra Mundial (1918) y el movimiento estudiantil de mayo de 1968, se produjeran obras como las de Karl Mannheim, Ennst Bloch, Martin Buber y Herbert Marcuse, que reivindicaban el concepto de utopía desde diversas perspectivas, todas ellas inspiradas por la cuestión del socialismo ${ }^{18}$.

El socialismo había pretendido, como la propia Utopía de Moro, responder al avance del capitalismo proponiendo un orden alternativo que restaurara la armonía social sobre nuevas bases. La esperanza de ese mundo alternativo ha sido la gran utopía de los siglos contemporáneos. Como afirmó Bauman, las definiciones y debates sobre la utopía y lo utópico han estado condicionados por las percepciones del socialismo a lo largo de los siglos XIX y XX ${ }^{19}$; y, en la medida en que consideremos -como él- que la utopía es necesaria para orientar la lucha por un mundo mejor, la crisis del socialismo nos ha abocado a un mundo huérfano de utopías.

Se ha hablado, para referirse al periodo que vivimos desde finales del siglo XX, de la "muerte" o el "fin de las utopías", después de las grandes "fiestas utópicas" que nos deparó aquel siglo (revoluciones, guerrillas, militancias de todo tipo... hasta llegar a la gran explosión de Mayo del 68). Nuestro tiempo, pues, se caracterizaría por la "condición antiutópica": es un tiempo de pragmatismo, consumismo e individualismo, en el que se considera absurdo perseguir grandes ideales o albergar esperanzas de un mundo mejor. En este mundo, en el que incluso la literatura utópica ha perdido atractivo para los editores, la lucha contra el sistema se da por perdida y ha quedado abandonada; si persisten utopías, son más bien testimoniales, de pequeña escala y aprovechando los pocos resquicios que deja un capitalismo triunfante.

${ }^{18}$ Ernst Bloch, Geist der Utopie (Múnich-Leipzig: Duncker und Humblot, 1918); Karl Mannheim, Ideología y utopía... (1929); Ernst Bloch, El principio esperanza (1938-1947) (Madrid: Trotta, 2004), 3 vols.; Martin Buber, Caminos de utopía (1947) (México: Fondo de Cultura Económica, 1955); Herbert Marcuse, El final de la utopía (1967) (Barcelona: Ariel, 1968).

${ }^{19}$ Zygmunt Bauman, Socialismo: la utopía activa (1976) (Buenos Aires: Nueva Visión, 2012). 
Esa percepción procede de la crisis del socialismo, que ha tenido dos facetas paralelas. Por un lado, la crisis del marxismo-leninismo: si el desarrollo del "socialismo real" en la URSS estimuló tanto el utopismo de algunos como las advertencias distópicas de otros, su crisis a finales del siglo XX determinó una crisis generalizada de la esperanza utópica. De hecho, desde la desaparición de la Unión Soviética la crisis del marxismo se acepta como un hecho consumado. Pero no menos cierta es la crisis del socialismo reformista y democrático: los partidos socialdemócratas europeos han acabado por convertirse en cómplices necesarios para el sostenimiento del orden neoliberal, sin asomo de tensión crítica, de utopismo ni de deseo alguno de cambio.

En este momento en que parecen esfumarse a la vez el socialismo y la utopía la adopción de una perspectiva histórica nos permite concluir con dos ideas importantes. Por un lado, que a lo largo de los últimos siglos se han dado varios ciclos de auge y de decadencia del impulso utópico, en los que alternativamente el concepto de utopía ha sido desprestigiado y reivindicado. Con esa perspectiva, los tiempos recientes en los que la utopía pareció morir definitivamente, o al menos quedar anticuada, podrían ser parte de uno más de esos ciclos, que incluso pudiera estar cambiando ya de signo hacia nuevas esperanzas de mundos posibles. Por otro lado, que el socialismo decepcionante que hemos conocido en los últimos tiempos no es tampoco el único posible. El comunismo y la socialdemocracia del siglo XX agotaron su capacidad emancipadora y ya no despiertan esperanzas. Pero el impulso crítico y ético que latía detrás de la Utopía original de Tomás Moro, latía también en la lucha contra el capitalismo que emprendieron los primeros socialistas. Saltan a la vista los retazos de Moro en los falansterios de Fourier, en las Home colonies de Owen o en la Icaria de Cabet. Todos los socialismos se han mirado en el espejo de Utopía. Y cuando se han alejado de ese referente utópico, han dejado de ser socialismos. Por lo que sería tal vez el momento de volver la mirada hacia el ingente depósito de ideas emancipadoras que había en aquel socialismo utópico, despreciado en su momento y con posible valor de utopía activa aún en nuestros días.

\section{BIBLIOGRAFÍA}

Baralt, Rafael María de, Diccionario de galicismos: o sea de las voces, locuciones y frases de la lengua francesa que se han introducido en el habla castellana moderna (Madrid: Imprenta Nacional, 1855).

Bauman, Zygmunt, Socialismo: la utopía activa (Buenos Aires: Nueva Visión, 2012).

Blanqui, Adolphe-Jérôme, Histoire de l'économie politique en Europe depuis les anciens jusqu'à nos jours, suivie d'une bibliographie raisonnée des principaux ouvrages d'économie politique (París, Guillaumin, 1837). Ed. española: Historia de la economia política en Europa: 
desde los tiempos antiguos hasta nuestros dias, seguida de una bibliografía razonada de las principales obras de dicha ciencia (Madrid: Imp. de Nicolás Arias, 1839).

Bloch, Ernst, Geist der Utopie (Múnich-Leipzig: Duncker und Humblot, 1918).

Bloch, Ernst, El principio esperanza (Madrid: Trotta, 2004), 3 vols.

Buber, Martin, Caminos de utopía (México: Fondo de Cultura Económica, 1955).

Chao, Eduardo, dir., Diccionario enciclopédico de la lengua española: con todas las vozes, frases, refranes y locuciones usadas en España y las Américas españolas, en el lenguaje común antiguo y moderno; las de ciencias, artes y oficios; las notables de historia, de biografia, de mitolojía y geografía universal, y todas las particulares de las provincias españolas y americanas, (Madrid: Imprenta y Librería de Gaspar y Roig, 1853-1855), 2 vols.

Doren, Alfred. "Wunschräume und Wunschzeiten", en Vorträge der Bibliothek Warburg 1924/ 25 (Leipzig-Berlín: Teubner, 1927), 158-205.

Engels, Federico, Del socialismo utópico al socialismo científico (Madrid: Ricardo Aguilera, 1969).

Fernández, Graciela, Utopía. Contribución al estudio del concepto (Mar del Plata: Suárez, 2005).

Hugo, Victor, Los miserables (Madrid: Alianza Editorial, 2013).

Leroux, Pierre, De l'égalité, précédé de De l'individualisme et du socialisme (Ginebra: Slatkine, 1996).

Mannheim, Karl, Ideología y utopía. Introducción a la sociología del conocimiento (Madrid: Aguilar, 1973).

Marcuse, Herbert, El final de la utopía (Barcelona: Ariel, 1968).

Marx, Karl y Friedrich Engels, Manifiesto Comunista (Madrid: Alianza Editorial, 2001).

Mercier, Louis-Sébastien, L'an deux mille quatre cent quarante. Rêve s'il en fût jamais (Londres, en realidad, Ámsterdam: E. Van Harrevelt, 1771). Ed. española: El año 2440. Un sueño como no ha habido otro (Madrid: Akal, 2016).

Moro, Tomás, De optimo reipublicae statu, deque nova insula V topiae (Lovaina: Dirk Martens, 1516).

Owen, Robert y John Brindley, What is Socialism? And what Would be Its Practical Effects Upon Society? A Correct Report of the Public Discussion Between Robert Owen \& Mr. 
John Brindley, Held in Bristol, on the 5th, 6th, and 7th of January, 1841 (Londres: Home Colonization Society, 1841).

Pastor Díaz, Nicomedes, Discursos (Barcelona: Anthropos-Fundación Caja Madrid, 1996).

Pastor Díaz, Nicomedes, Los problemas del socialismo: lecciones pronunciadas en el Ateneo de Madrid en el curso de 1848 a 1849 (Madrid: Imp. de Manuel Tello, 1867).

Pro, Juan. "Utopia in the Spanish Language: the Origin of a Word, the History of an Idea", en Utopias in Latin America: Past and Present, ed. J. Pro (Brighton-Portland: Sussex Academic Press, 2018), 15-35.

Real Academia Española, Diccionario de la lengua castellana 11ª edición (Madrid: Imp. De Manuel Rivadeneyra, 1869).

Reybaud, Louis, Études sur les reformateurs ou socialistes modernes, Saint-Simon, Charles Fourier, Robert Owen (París: Guillaumin, 1840).

Stein, Lorenz von, Der Sozialismus und Kommunismus des heutigen Frankreichs (Leipzig, Otto Wiegand, 1842).

Recibido:16 de marzo de 2017 Aprobado: 16 de octubre de 2017 